\title{
AN INVESTIGATION OF MANAGEMENT PRACTICES IN CHINESE SOCIAL ENTERPRISES
}

\author{
Long Wang ${ }^{1}$ and Yanto Chandra ${ }^{2}$ \\ ${ }^{1}$ City University of Hong Kong, Hong Kong \\ ${ }^{2}$ The Hong Kong Polytechnic University, Hong Kong
}

\begin{abstract}
Despite the growing popularity of social enterprises (SE) in the Chinese context, scholarly research on Chinese social enterprises is rare, and the few that exist are either conceptual or descriptive (Chan et al., 2011; Chan \& Yuen, 2013; Ho \& Chan, 2010; Kuan et al., 2011). Based on our extensive review of the SE literature, the management aspects of Chinese social enterprises (i.e., social enterprises that originate from Taiwan, Hong Kong and China) have received little attention. To-date, we know too little about the management practices of social enterprises in the Chinese context. Given the unique historical, institutional, cultural and philosophical roots of the Chinese societies (Pun et al., 2000; Tsui, 2007), it is likely that the meaning, purpose, and management of Chinese social enterprises have certain uniqueness or indigenous characteristics that may not be found in the Western countries. These efforts could lead to a proliferation of new research agendas and a contextualized theory of what works or not in the Chinese SE context.

In the current research, we argue that SE is a distinctive sector and is different from the for-profit sector. Hence, there may be novel Chinese social enterprise's management practices that are not yet known or hidden but could inform future theory development and testing. In particular, we will have a deeper understanding of the universalism and particularism of management theories in the SE context by investigating 1) how and why well-established management theories from the West may apply to Chinese social enterprises; 2) how Western theories may be adapted or fused with indigenous practices in the context of Chinese social enterprises; and 3) whether there are there are indigenous management practices from Chinese social entrepreneurs that can inform extant theories. Specially, we explored three concepts from the management literature that may explain the management practices of Chinese social enterprises: Intuitive-Aesthetic Strategy (Pun et al., 2000; Luo, 2003; Barney \& Zhang, 2009), Yin-Yang Balance (the golden rule of balanced harmony; Chen \& Miller, 2011; Li, 2014); and Creative Imitation Strategy (Lee \& Hung, 2014; Huang, Chou, \& Lee, 2010; Luo et al., 2011) while also attempting to discover any new concepts from the data that might inform and extend theory. We employed inductive, theory-building research (Glaser, 1998; Strauss and Corbin, 1990) and choose six social enterprises that create "transformational impact" (two each from China, Hong Kong, and Taiwan) as 'strategic research site' to find the commonality and differences of the management practices of the Chinese social enterprises across these three different contexts. Our findings revealed more puzzles and heterogeneity than a homogeneity in the meaning and ways of managing of "transformational" social enterprises in this region. We found some support for the use of planned and intuitive approach to managing SE and the role of maintaining the balance of activities/events (Yin-Yang) but found that being innovative is more valued than being imitative. Confucian values were not as strongly embraced by the SE founders as we had expected. Some new concepts emerged that might be native to this context such as the role of Guanxi at the personal and organizational level, the size of a social problem (social market), growth intention, and unique marketing strategies - that help the SEs achieve "transformational impact" in their region. The findings offer important implications to SE theory, practice and for policy making.
\end{abstract}

\section{KEYWORDS}

Social Enterprises, Management Practices, Chinese Social Enterprises, Transformational Enterprises

\section{REFERENCES}

Barney, J., \& Zhang, Z. 2009. The Future of Chinese Management Research: A Theory of Chinese Management versus A Chinese Theory of Management. Management and Organization Review, 5(1): 15-28. 
Chan, K. T., et al. 2011. Similarities and divergences: comparison of social enterprises in Hong Kong and Taiwan. Social Enterprise Journal, 7(1), 33-49.

Chan, K. M., \& Yuen, Y. K. T. 2013. An overview of social enterprise development in China and Hong Kong. Journal of Ritsumeikan Social Sciences and Humanities, 5, 165-178.

Corbin, J. M., \& Strauss, A. 1990. Grounded theory research: Procedures, canons, and evaluative criteria. Qualitative Sociology, 13(1), 3-21.

Ho, A. P. Y., \& Chan, K. T. 2010. The social impact of work-integration social enterprise in Hong Kong. International Social Work, 53(1), 33-45.

Kuan, Y. Y., et al. 2011. The governance of social enterprise in Taiwan and Hong Kong: a comparison. Journal of Asian Public Policy, 4(2), 149-170.

Luo, Y., et al. 2011. Emerging economy copycats: Capability, environment and strategy. Academy of Management Perspective, 25(2): 37-56.

Poon, P. S., et al. 2009. Social entrepreneurship in a transitional economy entrepreneurial firms. Journal of Management Development, 28(2), 94-108.

Pun, K. F., et al. 2000. A review of the Chinese cultural influences on Chinese enterprise management. International Journal of Management Reviews, 2(4), 325-338. 